\title{
STATUS OF 25-HYDROXYVITAMIN D LEVELS AND SERUM CONCENTRATION OF PRO- INFLAMMATORY CYTOKINES (IL-6 AND TNF-A) IN MIDDLE-AGED TRIBAL SUBJECTS OF TRIPURA
}

\author{
Arkadip Choudhury1, Avik Chakraborty², Animesh Saha ${ }^{3}$ \\ 1Senior Resident, Department of General Medicine, Tripura Medical College and Dr. B. R. Ambedkar Memorial Teaching Hospital, \\ Agartala, Tripura, India. \\ 2Professor, Department of General Medicine, Tripura Medical College and Dr. B. R. Ambedkar Memorial Teaching Hospital, Agartala, \\ Tripura, India. \\ ${ }^{3}$ Research Assistant, Department of General Medicine, Tripura Medical College and Dr. B. R. Ambedkar Memorial Teaching Hospital, \\ Agartala, Tripura, India.
}

\begin{abstract}
\section{BACKGROUND}

There have been many studies conducted so far on Non-Alcoholic Fatty Liver Disease (NAFLD) with its many aspects including its association with 25-hydroxyvitamin D levels and its rather complex interplay with pro-inflammatory cytokines, such as Interleukin-6 (IL-6) and Tumour Necrosis Factor-Alpha (TNF- $\alpha$ ).

This study was designed to show the development of NAFLD in the young tribal population of Tripura and the link between 25 $(\mathrm{OH})$ Vitamin D and pro-inflammatory cytokines (IL-6 and TNF-a) and the development of NAFLD, while at the same time throws light on the prevalence of $25(\mathrm{OH})$ Vitamin D deficiencies and the levels of pro-inflammatory cytokines in the study group.
\end{abstract}

\section{MATERIALS AND METHODS}

The study is a case control study with final population of 94 cases between 18 and 40 years of age fulfilling inclusion and exclusion criteria and an equal number of subjects from same tribal community age and sex matched taken as control population.

\section{RESULTS}

There was a significant relationship between level of $25(\mathrm{OH})$ Vitamin D and fatty liver (OR: 9.46, 95\% CI: 4.82 - 18.59; p < 0.001$)$. The mean serum $25(\mathrm{OH})$ Vitamin D level in the cases was significantly higher than the controls $(17.21 \mathrm{ng} / \mathrm{mL} \pm 6.34 \mathrm{ng} / \mathrm{mL} \mathrm{vs}$ $26.56 \mathrm{ng} / \mathrm{mL} \pm 10.63 \mathrm{ng} / \mathrm{mL} ; \mathrm{p}<0.001$ ). There was a significant difference between the mean serum IL-6 levels of the cases and the controls $(2.99 \pm 1.11 \mathrm{pg} / \mathrm{mL}$ vs $2.22 \pm 1.08 \mathrm{pg} / \mathrm{mL} ; \mathrm{p}<0.001)$ and mean serum TNF- $\alpha$ levels of the cases and the controls $(6.99$ $\pm 2.81 \mathrm{pg} / \mathrm{mL}$ vs $5.40 \pm 3.08 \mathrm{pg} / \mathrm{mL} ; \mathrm{p}<0.001)$. Low serum $25(\mathrm{OH}) \mathrm{D}$ [OR: 0.87 (95\% CI: $0.83-0.92), \mathrm{p}=0.0001]$ and high IL-6 [OR: 1.71 (95\% CI: $1.23-2.38), p=0.0013$ ] and TNF- $\alpha$ [OR: 1.17 (95\% CI: $1.02-1.34$ ), $p=0.0232$ ] were independently associated with the risk of NAFLD.

\section{CONCLUSION}

$25(\mathrm{OH})$ Vitamin D concentration are lower, while that of IL-6 and TNF- $\alpha$ are higher in subjects with fatty liver in comparison to those without. $25(\mathrm{OH})$ Vitamin D deficiency and high levels of serum IL- 6 and TNF- $\alpha$ were independently associated with the risk of development of NAFLD.

\section{KEY WORDS}

25-Hydroxyvitamin D, Interleukin-6, Tumour Necrosis Factor-Alpha, Non-Alcoholic Fatty Liver Disease.

HOW TO CITE THIS ARTICLE: Choudhury A, Chakraborty A, Saha A. Status of 25-hydroxyvitamin D levels and serum concentration of pro-inflammatory cytokines (IL-6 and TNF- $\alpha$ ) in middle-aged tribal subjects of Tripura. J. Evolution Med. Dent. Sci. 2018;7(45):4847-4852, DOI: $10.14260 /$ jemds/2018/1080

\section{BACKGROUND}

Non-Alcoholic Fatty Liver Disease (NAFLD) is a disorder that is characterised by a group of histological abnormalities identified on liver biopsy, similar to those seen in alcoholic liver disease, but occurring in patients who consume little or no alcohol. It has a spectrum that ranges from simple fatty liver (steatosis) to Non-Alcoholic Steatohepatitis (NASH) and 'Financial or Other Competing Interest': Dr. Chakraborty reports grants from ICMR (under North East Seed Grant), outside the submitted work.

Submission 26-03-2018, Peer Review 15-10-2018,

Acceptance 25-10-2018, Published 05-11-2018.

Corresponding Author:

Dr. Avik Chakraborty,

Professor, Department of General Medicine,

Tripura Medical College and Dr. B. R. Ambedkar Memorial Teaching

Hospital, Hapania, Agartala-799014, Tripura-West, India.

E-mail: dravik1975@gmail.com

DOI: $10.14260 /$ jemds $/ 2018 / 1080$
NAFLD associated cirrhosis.[1] Worldwide prevalence reports of NAFLD vary widely between $2.8 \%$ and $46.0 \%$.[2] Laboratory and clinical evidence supports the fact that peripheral insulin resistance and hyperinsulinaemia are associated with NAFLD, even in lean patients without obvious glucose intolerance. Vitamin D is capable to reduce FFAinduced insulin resistance, both in peripheral tissues and in hepatocytes. Therefore, low serum vitamin D may predispose to intrahepatic lipid accumulation leading to NAFLD. A strong epidemiological overlap exists between NAFLD and hypovitaminosis D prevalence, as both conditions are widely spread among obese dysmetabolic individuals.[3,4] Vitamin D exerts a direct action on the liver through its specific receptor, VDR, expressed in all hepatic cell populations; notably, its expression negatively correlates with the inflammatory damage in chronic hepatic diseases. TNF- $\alpha$ receptor polymorphism is one type of genetic polymorphisms, which is overexpressed in patients with NAFLD who moved onto NASH. One of the major mechanisms 
by which TNF- $\alpha$ plays its role in NAFLD is by creating a state of insulin resistance by inhibiting the tyrosine kinase activity of the insulin receptor.[5] The connection between TNF- $\alpha$ expression and insulin resistance in NAFLD was first described by Hotamisligil et al in a study in which adipose tissue was presented as a significant cause of obesity induced inflammation, mainly by TNF- $\alpha$ expression inducing inflammation and insulin resistance.[6] IL-6 has a wide range of biological functions including induction of inflammation and oncogenesis, regulation of immune response and support of haematopoiesis. Though initially considered as a hepatoprotector in liver steatosis, capable of reducing oxidative stress and preventing mitochondrial dysfunction, IL-6 was found to be a key element in the acute phase response, mediating the synthesis of several acute phase proteins. It has been seen that not only the cytokine itself but also its soluble receptor is significantly increased in patients with NASH.[5] Therefore, the possibility that IL-6 may play an indirect deleterious role in NAFLD pathogenesis by sensitising the liver to injury, stimulating hepatocyte apoptosis and inducing insulin resistance cannot also be excluded.

\section{Aims and Objectives}

The aim of the present study is to investigate the relationship of Vitamin D status and Immunomodulators (TNF- $\alpha$, IL-6) as the indicators of NAFLD in middle-aged tribal subjects of Tripura. The objectives were to determine the status of 25 $(\mathrm{OH})$ Vitamin D concentration in middle-aged non-alcoholic tribal subjects of Tripura with and without fatty liver disease and to evaluate whether the risk of development of NAFLD in these subjects has any association with the level of Immunomodulators and Vitamin D status.

\section{MATERIALS AND METHODS}

The study is a case control study. A consecutive type of nonprobability sampling was carried out, where a total of 94 tribal subjects from two different communities across the state fulfilling inclusion and exclusion criteria and having ultrasound evidence of fatty liver were taken as cases. An equal number of age, sex and demography matched subjects from same tribal communities, but without evidence of fatty liver on ultrasonography were taken as the control population. The study population was collected from specially designed health camps conducted across various tribal belts of the state in association with the state chapter of the Indian Medical Association and the Hepatitis foundation of Tripura. A single observer-based screening ultrasonography was conducted in all these health camps to detect the non-alcoholic subjects with fatty liver to be selected as cases and non-alcoholic subjects of similar age, and other demographic factors without fatty liver to be selected as controls. Cut-Off BMI: $>23$ and $25 \mathrm{~kg} / \mathrm{m}^{2}$ for overweight and obesity respectively as per Asia Pacific Guidelines were implemented.

Sample Size for this Study has been calculated by the following Formula-

$n=\left(\frac{r+1}{r}\right) \frac{\left(S_{1}^{2}+S_{2}{ }^{2}\right)\left(Z_{\beta}+Z_{\alpha / 2}\right)^{2}}{(d)^{2}}$

\section{Where}

1. $\mathrm{n}=$ sample size.

2. $r=$ ratio of cases and controls (in our study number of cases and controls being equal, $r=1$ )

3. $Z_{\beta}=0.84$ for power of the study at being $80 \%$

4. $Z_{\alpha / 2}=1.96$ for level of significance at 0.05

5. $\mathrm{S}_{1}=9.2$ (Standard deviation of case) ${ }^{[6]}$

6. $\mathrm{S}_{2}=9.7$ (Standard deviation of control)[6]

7. $\mathrm{d}=$ Difference between means $(20.5-14.8=5.7)^{[6]}$

For power of the study at $80 \%$ and level of significance taken at $0.05, Z_{\beta}=0.84$ and $Z_{\alpha / 2}=1.96$, the required sample size was found to be 90 . Finally, 94 subjects with NAFLD were included in the study as cases with a similar number of age, sex and demography matched healthy volunteers as control subjects.

\section{Inclusion Criteria}

1. Referred for assessment of abnormal Liver Function Test (LFT) or hepatic steatosis detected by ultrasonography.

2. Age between 20 and 40 years.

3. Alcohol consumption less than ( $40 \mathrm{gm} /$ week).

4. Willing to participate in the study.

\section{Exclusion Criteria}

1. Final diagnosis other than NAFLD.

2. Secondary causes of steatohepatitis and drug-induced liver disease.

3. Any case of chronic liver disease.

Height, weight, waist and hip circumference and blood pressure of each subject were measured at the baseline visit. Enzyme-Linked Immunosorbent Assay (ELISAs) was used to measure the serum concentration of TNF- $\alpha$ and IL- 6 in the NAFLD and control subjects. Chemiluminescent assay was used to determine the serum levels of $25(\mathrm{OH})$ D. Liver Ultrasonography (US) scanning was performed to assess the degree of steatosis. All US were performed by the same operator who was unaware of the aims of the study and blinded to laboratory values using a US apparatus equipped with a convex $3.5 \mathrm{MHz}$ probe.

SPSS version 20 statistical package was used to perform the analysis. Student's T-test for continuous variables and $\chi^{2}$ test for categorical variables were used to compare mean values between two independent groups. $25(\mathrm{OH})$ Vitamin-D, IL- 6 and TNF- $\alpha$ were analysed as continuous variables. Data is shown as mean +/- standard $\mathrm{X}$ deviation. Receiver Operator Characteristic (ROC) curves were carried out to ascertain the usefulness of each of $25(\mathrm{OH})$ D, IL- 6 and TNF- $\alpha$ as predictors of NAFLD in the whole study. Binomial logistic regressions were carried out to ascertain whether each of 25 $(\mathrm{OH})$ D, IL-6 and TNF- $\alpha$ could independently predict the occurrence of NAFLD in the obese and non-obese subgroups. For all the above, a p-value $<0.05$ was considered statistically significant.

The study was funded by ICMR and the study protocol was approved by the Human Ethics Committee of the Tripura Medical College and Dr. BRAM Teaching Hospital and written informed consent were obtained in all cases. 


\section{RESULTS}

Of the 188 subjects who had enrolled in the study, maximum number (55/188, 29.3\%) belonged to the age group between 36 and 40 years. The mean age of the study population was 33.23 years with a standard deviation of 6.916 years. Of the 188 subjects 67 (35.6\%) subjects were male, whereas 121 (64.4\%) subjects were female. 62.23\% (117/188) subjects were obese, while $37.77 \%(71 / 188)$ were non-obese. Of the obese subjects $68.38 \%(80 / 117)$ had fatty liver on ultrasonography, whereas of the non-obese subjects only $19.72 \%(14 / 71)$ had fatty liver. Presence of obesity was significantly associated (Figure 1) with presence of fatty liver (odds ratio: 8.80, 95\% CI: $4.36-17.77$; $<0.001$ ). There was a significant difference (Figure 2) between the mean BMI of the cases and the controls $\left(25.70 \pm 2.93 \mathrm{~kg} / \mathrm{m}^{2}\right.$ vs $23.09 \pm$ $\left.3.17 \mathrm{~kg} / \mathrm{m}^{2} ; \mathrm{p}<0.001\right)$. 55.85\% (105/188) subjects had subnormal levels of $25(\mathrm{OH})$ Vitamin D, either insufficiency $(86 / 188,45.74 \%)$ or deficiency $(19 / 188,10.11 \%) .44 .15 \%$ $(83 / 188)$ subjects had normal levels of $25(\mathrm{OH})$ Vitamin D. Of the 105 subjects with subnormal levels of $25(\mathrm{OH})$ Vitamin D, $76(72.38 \%)$ had liver fat on ultrasonography, whereas of the 83 subjects with normal levels of $25(\mathrm{OH})$ Vitamin D only 18 (21.69\%) had fatty liver. There was a significant relationship between level of $25(\mathrm{OH})$ Vitamin $\mathrm{D}$ and fatty liver. $\mathrm{P}<0.001$ (Odds ratio: 9.46, 95\% CI: 4.82 - 18.59). Figure 3 shows the relationship.

The mean serum $25(\mathrm{OH})$ Vitamin D level in the cases that is those with fatty liver was $17.21 \mathrm{ng} / \mathrm{mL} \pm 6.34 \mathrm{ng} / \mathrm{mL}$, while the mean serum $25(\mathrm{OH})$ Vitamin D level in the control group was $26.56 \mathrm{ng} / \mathrm{mL} \pm 10.63 \mathrm{ng} / \mathrm{mL}$ (Figure 4). There was a significant difference $(\mathrm{p}<0.001)$ between the mean serum 25 $(\mathrm{OH})$ Vitamin D of the cases and the controls.

There was a significant difference $(\mathrm{p}<0.001)$ between the mean serum IL-6 levels of the cases and the controls (2.99 $\pm 1.11 \mathrm{pg} / \mathrm{mL}$ vs $2.22 \pm 1.08 \mathrm{pg} / \mathrm{mL}$ ) (Figure 5). There was a significant difference $(\mathrm{p}<0.001)$ between the mean serum TNF- $\alpha$ levels of the cases and the controls $(6.99 \pm 2.81 \mathrm{pg} / \mathrm{mL}$ vs $5.40 \pm 3.08 \mathrm{pg} / \mathrm{mL}$ ), (Figure 6).

Analysis of ROC curve for $25(\mathrm{OH})$ D showed an AUROC curve in NAFLD group (AUC $=0.790 ; 95 \%$ CI [0.724 - 0.846], $\mathrm{p}<0.0001$ ) (Figure 7A). The optimal cut-off value of $25(\mathrm{OH})$ D for NAFLD was $20.75 \mathrm{ng} / \mathrm{mL}$, below which NAFLD could be predicted with a sensitivity of $84.04 \%$ and a specificity of $68.09 \%$. When the ROC curve for IL-6 was analysed, it showed an AUROC curve in NAFLD group (AUC=0.703; 95\% CI $[0.632-0.767], \mathrm{p}<0.0001$ ) (Figure 7B). The optimal cutoff value of IL-6 for NAFLD was $2.08 \mathrm{pg} / \mathrm{mL}$, above which NAFLD could be predicted with a sensitivity of $78.72 \%$ and a specificity of $58.5 \%$. Analysis of ROC curve for TNF- $\alpha$ showed an AUROC curve in NAFLD group (AUC $=0.694 ; 95 \% \mathrm{CI}[0.623$ - 0.759], $p<0.001$ ) (Figure 7C). The optimal cut-off value of TNF- $\alpha$ for NAFLD was $5.50 \mathrm{pg} / \mathrm{mL}$, above which NAFLD could be predicted with a sensitivity of $61.70 \%$ and a specificity of 74.19\%.

Binomial logistic regressions showed that low serum 25 (OH) D [OR: 0.87 (95\% CI: $0.83-0.92$ ), $p=0.0001$ ] and high serum IL-6 [OR: 1.71 (95\% CI: $1.23-2.38$ ), $\mathrm{p}=0.0013$ ] and TNF- $\alpha$ [OR: 1.17 (95\% CI: $1.02-1.34$ ), $\mathrm{p}=0.0232$ ] were independently associated with the risk of NAFLD in the study population. Table 1 depicts the scenario.
The serum level of IL-6 was marginally lower (2.986 \pm $1.17 \mathrm{pg} / \mathrm{mL}$ vs $2.992 \pm 0.83 \mathrm{pg} / \mathrm{mL}, \mathrm{p}=0.980$ ), while the serum level of TNF- $\alpha$ was marginally higher $(7.03 \pm 2.83$ $\mathrm{pg} / \mathrm{mL}$ vs $6.81 \pm 2.77, \mathrm{p}=0.758)$ in subjects with $25(\mathrm{OH}) \mathrm{Vit}$ $\mathrm{D}$ deficiency compared to those without.

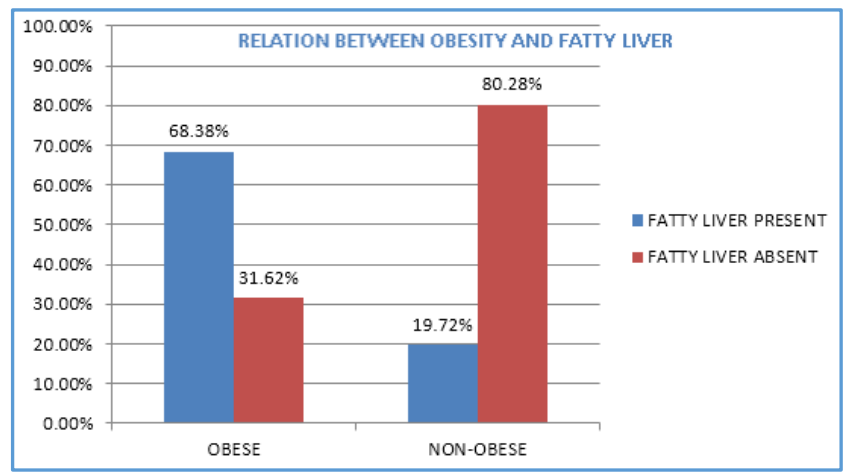

Figure 1. Bar diagram showing the relationship between obesity and fatty liver

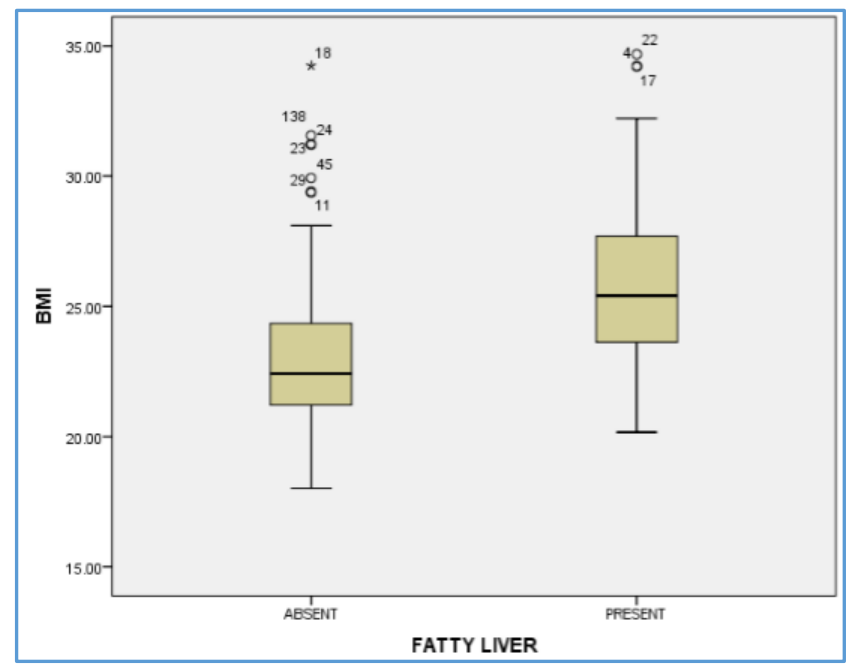

Figure 2. Box plot showing the distribution of BMI in the case and control groups

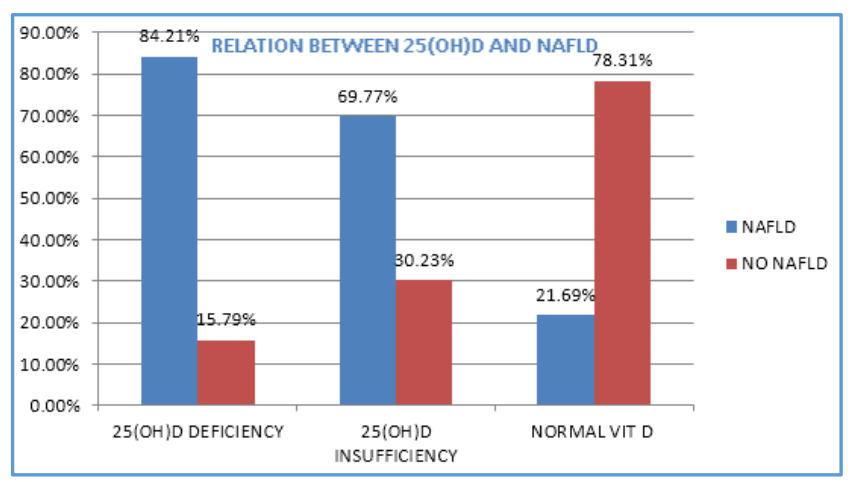

Figure 3. Bar diagram showing the relationship between level of 25(OH) Vitamin $D$ and fatty liver. $p<0.001$ (Odds ratio: 9.46, 95\% CI: 4.82 - 18.59: when calculated as only 25(OH) D deficiency absent or present) 


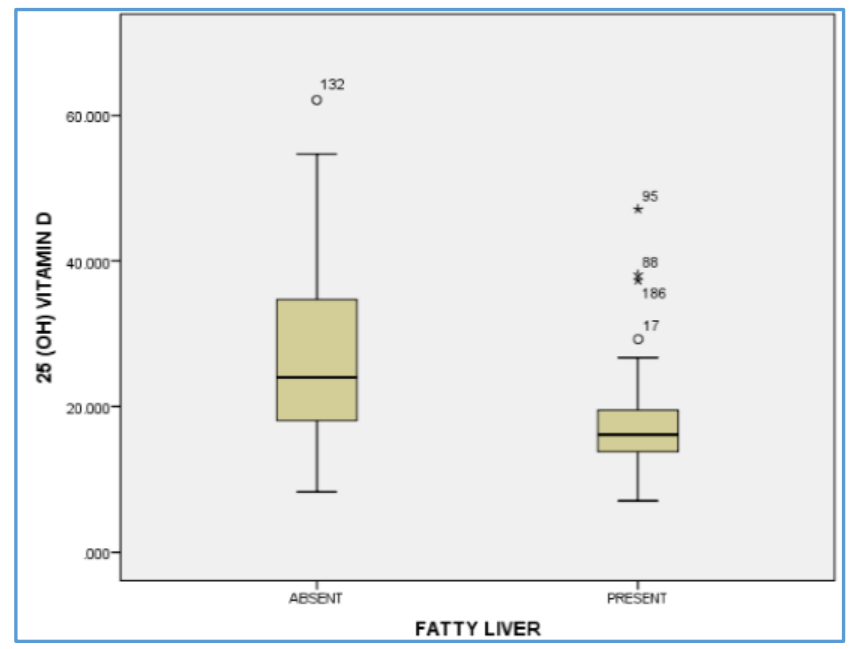

Figure 4. Box plot showing the serum levels of 25(OH) Vitamin $D$ in the case and control groups

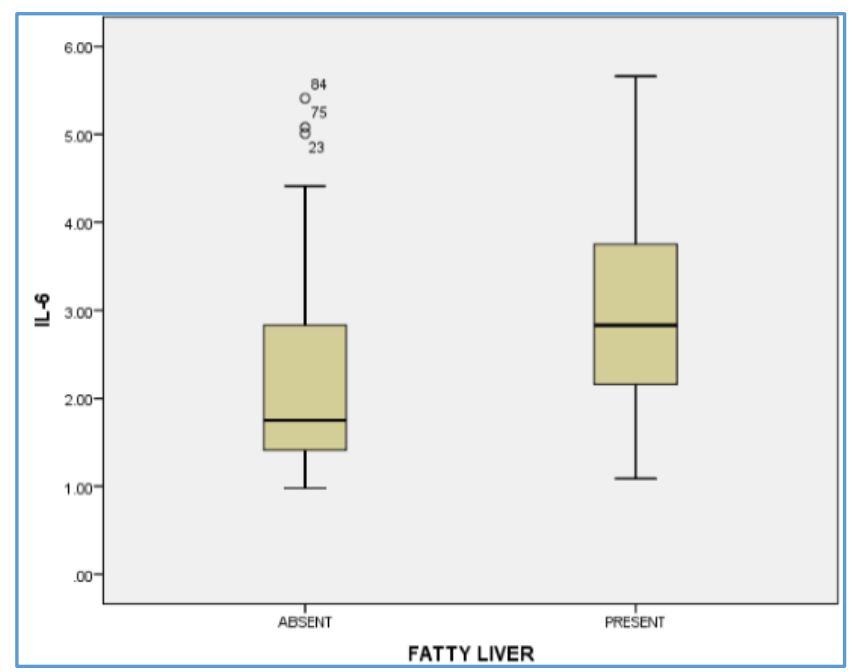

Figure 5. Box plot showing the serum levels of IL-6 in the case and control groups

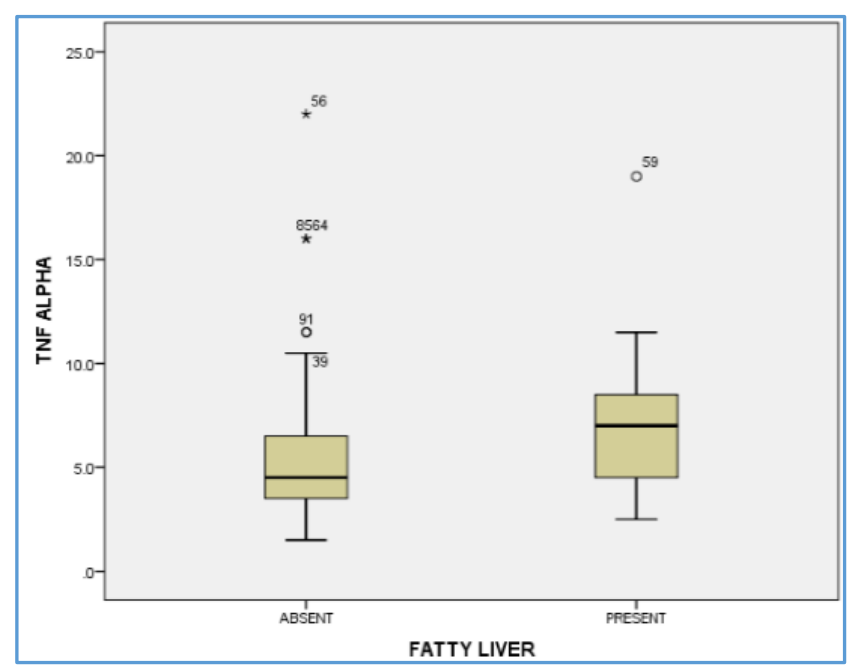

Figure 6. Box plot showing the serum levels of TNF- $\alpha$ in the case and control groups

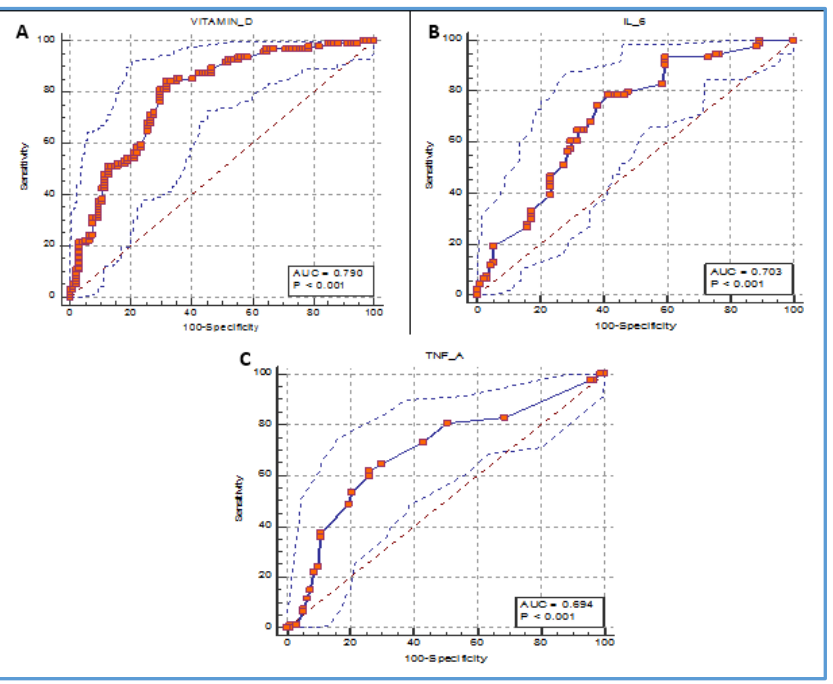

Figure 7A. ROC of $25(\mathrm{OH}) \mathrm{D}$ for NAFLD

Figure $7 B$. ROC of IL-6 for NAFLD

Figure 7C. ROC of TNF- $\alpha$ for NAFLD

\begin{tabular}{|c|c|c|c|c|}
\hline \multicolumn{5}{|c|}{ Results of Binomial Logistic Regression Analysis } \\
\hline Parameters & $\begin{array}{c}\text { Odds } \\
\text { Ratio }\end{array}$ & $\mathbf{9 5 \%}$ CI & $\begin{array}{c}\text { Co } \\
\text { efficient }\end{array}$ & p value \\
\hline $\begin{array}{c}25(\mathrm{OH}) \\
\text { Vitamin D }\end{array}$ & 0.87 & $0.83-0.92$ & -0.13449 & $<0.0001$ \\
\hline IL-6 & 1.71 & $1.23-2.38$ & 0.53873 & 0.0013 \\
\hline \multicolumn{6}{|c|}{ TNF- $\alpha$} & 1.17 & $1.02-1.34$ & 0.15832 & 0.0232 \\
\hline $\begin{array}{c}\text { Table 1. Showing outcome of binary logistic regression } \\
\text { analysis for the assessment of 25(OH) D, IL-6, TNF- } \alpha \text { as } \\
\text { predictors of the risk of developing NAFLD }\end{array}$ \\
\hline
\end{tabular}

\section{DISCUSSION}

The study sample was selected on a strict 1: 1 pattern. While most of the other similar studies have not followed a 1: 1 sampling, studies conducted by Jablonski et al[7] and that conducted by Targher $\mathrm{G}$ et al[8] have taken equal number of matched cases and controls.

Majority of the subjects, $(62.23 \%)$ subjects were obese and majority (68.38\%) of the obese subjects had fatty liver on ultrasonography. Presence of obesity was significantly associated with presence of fatty liver. There was a significant difference between the mean BMI of the cases and the controls. This study revealed a significant relationship between level of $25(\mathrm{OH})$ Vitamin $\mathrm{D}$ and fatty liver. The mean serum $25(\mathrm{OH})$ D levels in the cases was significantly lower than that found in the control subjects. The results were in unison with those seen in the studies conducted by Wang D et al,[9] Zhai HL et al,[10] Wang X et al[11] and Kucukazman et al[12] demonstrated that in contrast to the control group the cases with NAFLD in their study had significantly lower levels of 25 $(\mathrm{OH}) \mathrm{D}(12.3 \pm 8.9 \mathrm{ng} / \mathrm{mL}$ vs $20.0 \pm 13.6 \mathrm{ng} / \mathrm{mL}, \mathrm{p}<0.001)$. Hao $Y$ et al[13] demonstrated similar results in their study where vitamin D levels were significantly lower in the NAFLD group $(15.65 \pm 5.89 \mathrm{ng} / \mathrm{mL}$ vs $13.46 \pm 4.65 \mathrm{ng} / \mathrm{mL}, \mathrm{p}=0.002)$. Jablonski et al demonstrated a significantly lower $25(\mathrm{OH}) \mathrm{D}$ level in NAFLD patients as compared to the controls $(30 \pm 7$ $\mathrm{ng} / \mathrm{mL}$ vs $34 \pm 8 \mathrm{ng} / \mathrm{mL}, \mathrm{p}<0.001)$. Bhatt SP et al[14] and Barchetta et al[15] in their studies showed that low serum 25 $(\mathrm{OH}) \mathrm{D}$ was independently associated with NAFLD, which was also the scenario in the present study. Studies conducted by Targher $\mathrm{G}$ et al[8] and Black et al[16] also showed similar results. 
The level of serum IL- 6 was significantly greater in the NAFLD group than in the non-NAFLD group. In a study conducted by Kumar et al,[17] IL-6 showed marked and selective increase only in the NAFLD patients ( $\mathrm{p}<0.02)$. Mohamed AA et al[18] found IL- 6 to be higher in NAFLD than control, though not significant $(114.24 \pm 22.32 \mathrm{pg} / \mathrm{mL}$ vs $104.9 \pm 19.98 \mathrm{pg} / \mathrm{mL}$ ). Taratino $\mathrm{G}$ et al[19] found significantly higher IL-6 levels in NASH patients, while Hasan K et al[20] and Cosma $\mathrm{M}^{[21]}$ also in their respective comprehensive reviews on NAFLD made a mention of IL- 6 to be increased or involved as possible mechanism in fatty liver disease.

Level of serum TNF- $\alpha$ was also significantly greater in the NAFLD group than in the non-NAFLD group. Chu CJ et al[22] found TNF- $\alpha$ to be significantly higher in NAFLD than control subjects $(2.63 \pm 0.44 \mathrm{pg} / \mathrm{mL}$ vs $1.56 \pm 0.10 \mathrm{pg} / \mathrm{mL}, \mathrm{p}=0.016)$. Krawczyk K et al[23] found higher mean serum TNF- $\alpha$ levels in NASH group compared to controls $(34.2 \pm 19.7 \mathrm{pg} / \mathrm{mL}$ vs 20.7 $\pm 15.5 \mathrm{pg} / \mathrm{mL}, \mathrm{p}<0.05$ ).

High serum concentrations of both IL- 6 and TNF- $\alpha$ were associated with the risk of development of NAFLD independent of each other and that of the serum levels of 25 $(\mathrm{OH})$ Vitamin D.

However, there was no significant relationship between the serum levels of Vitamin D status and those of the two immunomodulators, IL-6 ( $p=0.98)$ and TNF-a $(p=0.758)$ found in this study.

\section{CONCLUSION}

$25(\mathrm{OH})$ Vitamin D concentration are low in middle-aged (20 40 years) tribal subjects with fatty liver in comparison to those without fatty liver. The concentrations of serum IL-6 and TNF- $\alpha$ are higher in subjects with fatty liver.

Besides, it was seen that $25(\mathrm{OH})$ Vitamin D deficiency and high levels of serum IL- 6 and TNF- $\alpha$ were independently associated with the risk of development of NAFLD, both in obese and non-obese individuals. Having done so, it gives us values of serum $25(\mathrm{OH})$ Vitamin D, IL-6 and TNF- $\alpha$ which can be used as cut-offs for predicting the risk of development of NAFLD with reasonable sensitivity and specificity.

This study thereby gives us an impression about status of $25(\mathrm{OH})$ Vitamin D concentrations in the middle-aged tribal subjects of Tripura. It also shows the relationship of the status of $25(\mathrm{OH})$ Vitamin D, IL-6 and TNF- $\alpha$ concentration in serum with NAFLD. There was however no significant relationship between Vitamin $\mathrm{D}$ status and the two immunomodulators (IL-6 and TNF-a).

However, in order to come to a definitive conclusion, further studies involving larger number of subjects and follow-up are needed.

\section{ACKNOWLEDGEMENTS}

The study group is thankful to the Indian Council for Medical Research for the funding and Tripura Medical College and Dr. B. R. Ambedkar Memorial Teaching Hospital for providing the setup for conducting the study. The study group is also thankful to the Hepatitis Foundation of Tripura and Indian Medical Association, Tripura State Branch for their valuable support in reaching out to the far-flung areas of the state for the purpose of collection of samples.

\section{REFERENCES}

[1] Neuschwander-Tetri BA. NASH. In: Boyer TD, Wright TL, Manns MP, eds. Zakim and Boyer's Hepatology: a textbook of liver diseases. $5^{\text {th }}$ edn. Elsevier 2006: p. 1031.

[2] Reid AE. Non-alcoholic fatty liver disease. In: Feldman M, Friedman LS, Brandt LJ, eds. Sleisenger and Fordtran's Gastrointestinal and Liver disease. $10^{\text {th }}$ edn. Elsevier 2016: p. 1428-9.

[3] Barchetta I, De Bernardinis M, Capoccia D, et al. Hypovitaminosis D is independently associated with metabolic syndrome in obese patients. PLoS One 2013;8(7):e68689.

[4] Mutt SJ, Hyppönen E, Saarnio J, et al. Vitamin D and adipose tissue-more than storage. Front Physiol 2014;5:228.

[5] Pearce SG, Thosani NC, Pan JJ. Noninvasive biomarkers for the diagnosis of steatohepatitis and advanced fibrosis in NAFLD. Biomarker Research 2013;1(1):7.

[6] Hotamisligil GS, Shargill NS, Spiegelman BM. Adipose expression of tumor necrosis factor-alpha: direct role in obesity-linked insulin resistance. Science 1993;259(5091):87-91.

[7] Jablonski KL, Jovanovich A, Holmen J, et al. Low 25hydroxyvitamin $\mathrm{D}$ level is independently associated with non-alcoholic fatty liver disease. Nutrition Metabolism and Cardiovascular Diseases 2013;23(8):792-8.

[8] Targher G, Bertolini L, Scala L, et al. Associations between serum 25-hydroxyvitamin D 3 concentrations and liver histology in patients with non-alcoholic fatty liver disease. Nutrition, Metabolism and Cardiovascular Diseases 2007;17(7):517-24.

[9] Wang D, Lin H, Xia M, et al. Vitamin D levels are inversely associated with liver fat content and risk of non-alcoholic fatty liver disease in a Chinese middleaged and elderly population: The Shanghai Changfeng Study. PLoS One 2016;11(6):e0157515. http://dx.doi.org/10.1371/journal.pone.0157515 [Retrieved 2016 Sep 29].

[10] Zhai HL, Wang NJ, Han B, et al. Low vitamin D levels and non-alcoholic fatty liver disease, evidence for their independent association in men in East China: a cross sectional study (Survey on prevalence in East China for metabolic diseases and risk factors (SPECTChina)). Br J Nutr 2016;115(8):1352-9.

[11] Wang X, Li W, Zhang Y, et al. Association between vitamin $\mathrm{D}$ and non-alcoholic fatty liver disease/nonalcoholic steatohepatitis: results from a meta-analysis. Int J Clin Exp Med 2015;8(10):17221-34.

[12] Küçükazman M, Ata N, Dal K, et al. The association of vitamin D deficiency with non-alcoholic fatty liver disease. Clinics (Sao Paulo) 2014;69(8):542-6.

[13] Hao YP, Ma XJ, Luo YQ, et al. Serum vitamin D is associated with non-alcoholic fatty liver disease in Chinese males with normal weight and liver enzymes. Acta Pharmacol Sin 2014;35(9):1150-6. 
[14] Bhatt SP, Nigam P, Misra A, et al. Independent associations of low 25 hydroxy vitamin $\mathrm{D}$ and high parathyroid hormonal levels with non-alcoholic fatty liver disease in Asian Indians residing in north India. Atherosclerosis 2013;230(1):157-63.

[15] Barchetta I, Angelico F, Del Ben M, et al. Strong association between non-alcoholic fatty liver disease (NAFLD) and low 25(OH) vitamin D levels in an adult population with normal serum liver enzymes. BMC Med 2011;9:85.

[16] Black LJ, Jacoby P, Ping-Delfos SWC, et al. Low serum 25-hydroxyvitamin D concentrations associate with non-alcoholic fatty liver disease in adolescents independent of adiposity. Journal of Gastroenterology and Hepatology 2014;29(6):1215-22.

[17] Kumar R, Prakash S, Chhabra S, et al. Association of pro-inflammatory cytokines, adipokines \& oxidative stress with insulin resistance \& non-alcoholic fatty liver disease. The Indian Journal of Medical Research 2012;136(2):229-36.

[18] Mohamed AA, Shousha WG, Shaker O, et al. Role of serum Adiponectin, IL-6 and Hs CRP in non-alcoholic fatty liver Egyptian patients. International Journal of Biochemistry Research \& Review 2014;4(6):493-504.
[19] Tarantino G, Conca P, Pasanisi F, et al. Could inflammatory markers help diagnose non-alcoholic steatohepatitis? European Journal of Gastroenterology \& Hepatology 2009;21(5):504-11.

[20] Hassan K, Bhalla V, El Regal ME, et al. Non-alcoholic fatty liver disease: a comprehensive review of a growing epidemic. World J Gastroenterol 2014;20(34):12082-101.

[21] Cosma M. The impact of Cytokines and Chemokines on Non-Alcoholic Fatty Liver Disease (NAFLD). BMBN 2014;2(1):15-6.

[22] Chu CJ, Lu RH, Wang SS, et al. Risk factors associated with non-alcoholic fatty liver disease in Chinese patients and the role of tumor necrosis factor-alpha. Hepatogastroenterology 2007;54(79):2099-102.

[23] Krawczyk K, Szczesniak P, Kumor A, et al. Adipohormones as prognostric markers in patients with nonalcoholic steatohepatitis (NASH). J Physiol Pharmacol 2009;60(Suppl 3):71-5. 